\title{
Disseminated mucormycosis of an immunocompromised multiple myeloma patient: impact of biopsy of extramedullary tumours in refractory multiple myeloma
}

\author{
S. Gattenlöhner • C. Unzicker • S. Wörner • G. Stuhler • \\ H. Einsele • H. K. Müller-Hermelink
}

Received: 2 August 2008 / Accepted: 8 August 2008 / Published online: 29 August 2008

(C) The Author(s) 2008. This article is published with open access at Springerlink.com

\begin{abstract}
Dear Editor,
We present the case of a 43-year-old female patient with an anaplastic IgG kappa multiple myeloma (MM) confirmed by morphological and molecular genetic analyses showing a tumourous bone marrow infiltration by highly atypical plasma cells (Fig. 1a) with strong expression of the plasma cell marker CD138 (Fig. 1b) and the kappa light chain (Fig. 1c, d reveals negative staining for lambda light chain) as well as a monoclonal rearrangement of the immunoglobulin heavy chain (IgH; Fig. 1e). In her 4-year treatment history, she underwent conventional chemotherapies as well as two autologous and one allogeneic peripheral blood stem cell transplantation from a matched related donor. Ten months after the latter, she presented with tumourous lesions in the left acetabulum, soft tissue, liver and dura mater coincidental with serum IgG kappa increase ( $\operatorname{IgG} 2,400 \mathrm{mg} / \mathrm{dL}$, free kappa light chains $1,550 \mathrm{mg} / \mathrm{L}$ ), suggesting extramedullary manifestations of MM. After a third, salvage high-dose chemotherapy with autologous stem cell support, the patient received haploidentical blood stem cell transplantation [1] in partial remission. However, due to an enlargement of the extramedullar infiltrates with increasing $\operatorname{IgG}$ values and a antibiotic/antimycotic therapy comprising fluconazole $400 \mathrm{mg} /$ day, posaconazole $400 \mathrm{mg} /$ day, voriconazole
\end{abstract}

\footnotetext{
S. Gattenlöhner $(\bowtie) \cdot S$. Wörner $\cdot H$. K. Müller-Hermelink Institute of Pathology, University of Würzburg,

Josef-Schneiderstr.2,

97080 Würzburg, Germany

e-mail: stefan.gattenloehner@mail.uni-wuerzburg.de

C. Unzicker $\cdot$ G. Stuhler $\cdot$ H. Einsele

Department of Internal Medicine, University of Würzburg,

Würzburg, Germany
}

$400 \mathrm{mg} /$ day, anidulafungin $100 \mathrm{mg} /$ day and caspofungin $50 \mathrm{mg} /$ day without substantial serological/microbiological hints at an infectious etiology, a renewed progression of MM was suspected. In a dramatically worsened terminal course with multiorgan failure and progressive cerebral clouding, the patient died under the suspicion of a progressive extramedullary relapsed anaplastic MM.

In autopsy, we found multiple nodular infiltrates in the liver (Fig. 2a, arrows) with parenchymatous scars and subacute infarctions (Fig. 2b) as well as a subtotal infarction of the right kidney and acute haemorrhagic infarctions of the lung and the cerebellum (Fig. 2d, arrow) showing fresh haemorrhages and necrosis in the cerebellar cortex (Fig. 2e). However, no residuals of the MM were detectable in the organ infiltrates neither by immunohistochemistry nor by molecular genetic analyses (Figs. 2c and f, showing polyclonal amplificates for the IgH rearrangement). By contrast, we could demonstrate an extensive vascular permeation with apparent occlusion of small to medium arteries by hyphae (Fig. 3) in all organs involved with subsequent haemorrhagic infarctions and the morphological diagnosis of mucormycosis (Fig. 3, inset) was confirmed by specific polymerase chain reaction amplification detecting Rhizopus species.

Extramedullary manifestations of MM occur in approximately $20 \%$ of patients and diffuse hepatic infiltration was even described in up to $50 \%$ of advanced cases [3]. However, since the differential diagnosis of extramedullary tumours in the refractory phase of MM includes other malignancies (e.g. transition to lymphoproliferative disorders [2]) as well as infectious diseases, a proper diagnostical clarification of any recurrent extramedullary tumour in MM by histological/molecular genetic analyses should be performed to improve the management and prognosis of such lesions. 
Fig. 1 Tumourous bone marrow infiltration by highly atypical plasma cells (a) with strong expression of the plasma cell marker CD138 (b) and the kappa light chain (c) as well as negative staining for lambda light chain (d) and a monoclonal rearrangement of the immunoglobulin heavy chain (e)

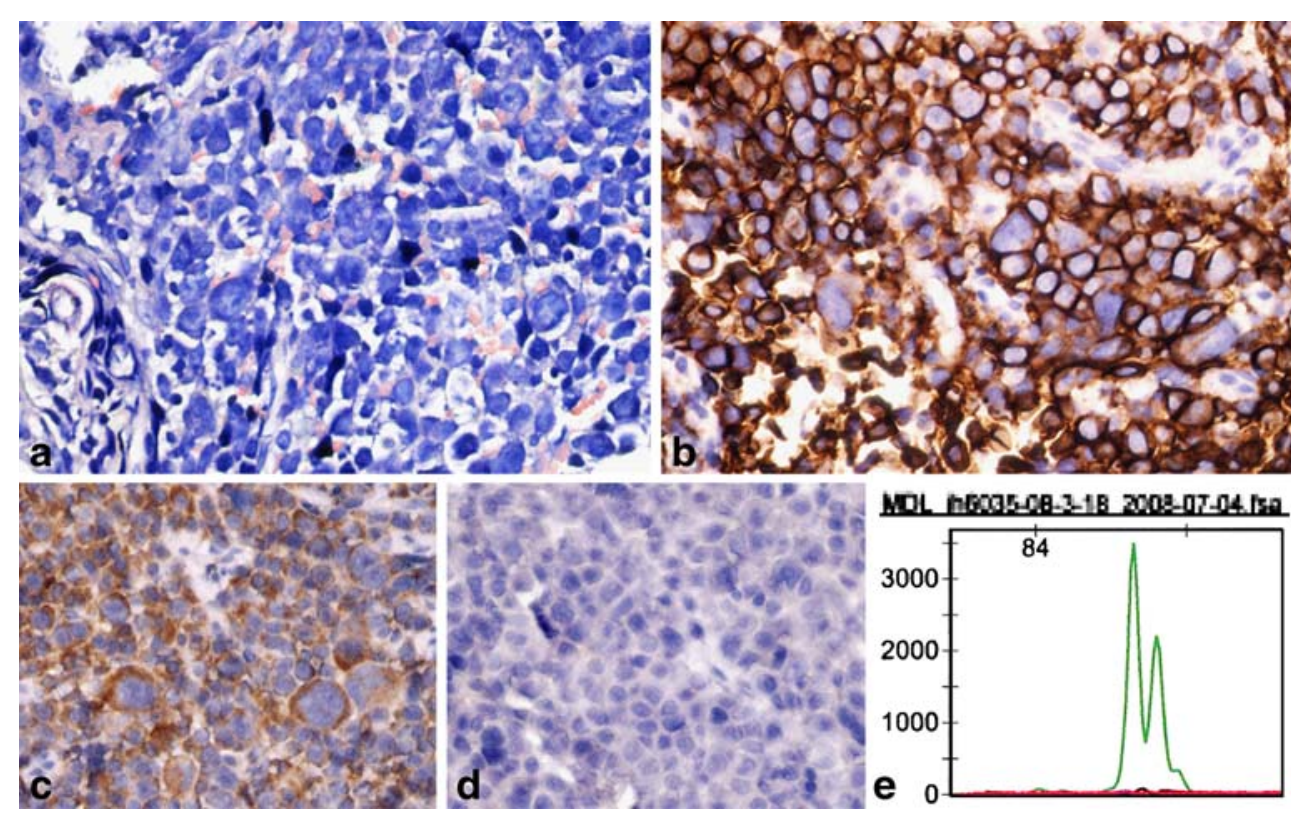

Fig. 2 Multiple nodular infiltrates in the liver (a, arrows) with parenchymatous scars and subacute infarctions (b) as well as a subtotal infarction of the right kidney and acute haemorrhagic infarctions of the lung and the cerebellum (d, arrow) showing fresh haemorrhages and necrosis in the cerebellar cortex (e). $\mathbf{c}$ and $\mathbf{f}$ Polyclonal amplificates for the IgH rearrangement
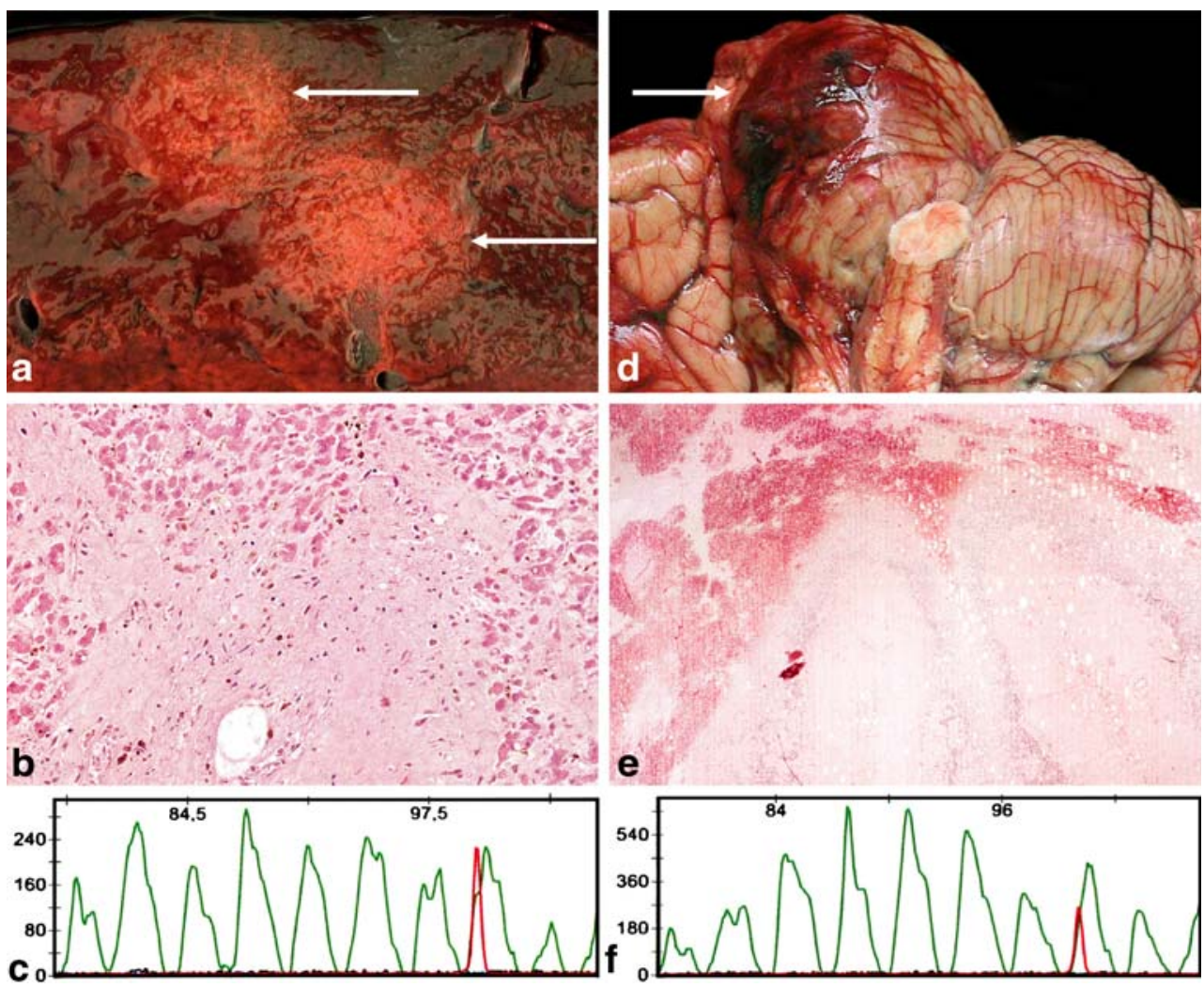


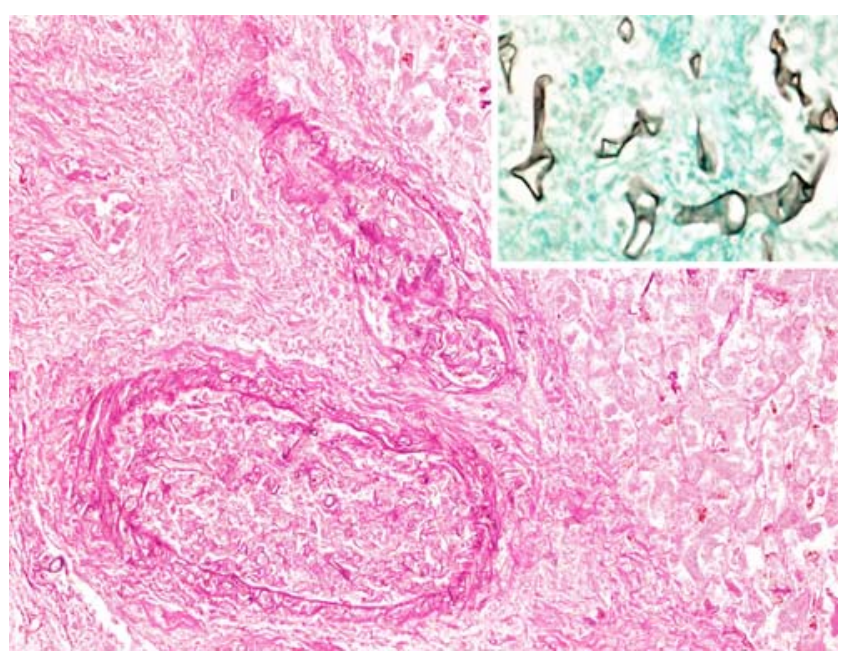

Fig. 3 Extensive vascular permeation with apparent occlusion of small to medium arteries by hyphae in all organs involved with subsequent haemorrhagic infarctions and the morphological diagnosis of mucormycosis (inset)
Open Access This article is distributed under the terms of the Creative Commons Attribution Noncommercial License which permits any noncommercial use, distribution, and reproduction in any medium, provided the original author(s) and source are credited.

\section{References}

1. Bethge WA, Faul C, Bornhauser M, Stuhler G, Beelen DW, Lang P et al (2008) Haploidentical allogeneic hematopoietic cell transplantation in adults using CD3/CD19 depletion and reduced intensity conditioning: an update. Blood Cells Mol Diseases 40:1319 doi:10.1016/j.bcmd.2007.07.001

2. Miwa A (2007) How to diagnose a patient precisely as a myeloma patient?-Lots of problems during diagnostic process. Nippon Rinsho 65:2268-2279

3. Perez Gil MA, Ruiz Recuento J, Relanzon Molinero S, Martinez Yunta JA (2006) Focal liver lesions in multiple myeloma: echography, computed tomography, and magnetic resonance findings. Radiologia 48:251-254 